Revista de la red interuniversitaria de estudios sobre las literaturas rioplatenses contemporáneas en Francia

16 | 2017

Esnobismos

\title{
La primavera social del esnob
}

Mariana Di Ció and Maya González Roux

\section{OpenEdition}

\section{Journals}

\section{Electronic version}

URL: http://journals.openedition.org/lirico/3783

DOI: $10.4000 /$ lirico.3783

ISSN: 2262-8339

\section{Publisher}

Réseau interuniversitaire d'étude des littératures contemporaines du Río de la Plata

\section{Electronic reference}

Mariana Di Ció y Maya González Roux, «La primavera social del esnob », Cuadernos LIRICO [En línea] 16 | 2017, Puesto en línea el 09 octubre 2017, consultado el 19 abril 2019. URL : http:// journals.openedition.org/lirico/3783; DOI : 10.4000/lirico.3783

This text was automatically generated on 19 April 2019

\section{cc) (i) ()}

Cuadernos LIRICO está distribuido bajo una Licencia Creative Commons Atribución-NoComercialSinDerivar 4.0 Internacional. 


\title{
La primavera social del esnob
}

\author{
Mariana Di Ció and Maya González Roux
}

1 Probablemente uno de los primeros esnobs del que tengamos noticias sea Petronio, considerado en la corte de Nerón como elegantiae arbiter o arbiter elegantiarum, es decir, autoridad en materia de costumbres y de etiqueta, al que Tácito describe en sus Anales como un ser "voluptuoso, lleno de refinamiento e imprudencia" (XVI, 18). Más allá del ejemplo ilustre, el esnob parece haber existido desde siempre: atraviesa los siglos adoptando distintas máscaras (burgués gentilhombre, preciosas ridículas durante el siglo XVII; Incroyables y Merveilleuses durante el Directorio; fashionables durante la Restauración) y una multitud de figuras polivalentes (el dandi, el escritor mundano o bien intelectual, el esnob de provincias, el anti-esnob o esnobista invertido...) pero es recién a mediados del siglo XIX cuando recibe verdaderamente sus títulos de nobleza, cuando el novelista inglés William Makepiece Thackeray publica en 1848 su Historia de los esnobs de Inglaterra, escrita por uno de ellos, cuyo título definitivo sería El libro de los esnobs. Figuras como Oscar Wilde, Virginia Woolf - que a mediados de los años treinta lee a sus amigos de Bloomsbury un texto llamado "¿Soy una esnob?" en el que por supuesto termina respondiendo de manera afirmativa - o Marcel Proust en Francia se convierten rápidamente en referentes ineluctables pero también en maestros de muchos escritores esnobs.

2 En un episodio de À la recherche du temps perdu, en el que el narrador reconoce el placer que siente al frecuentar los salones, y en particular el de Mme de Montmorency, Proust actúa como verdadero sociólogo del esnobismo y ofrece una metáfora floral para definir al esnob : "[Quelqu'un] dans l'imagination [duquel] fleurit tout un printemps social." ${ }^{1} \mathrm{La}$ "primavera social" podría entenderse como la "topografía social" detrás de la cual se esconden las aspiraciones del esnob : ante todo, el esfuerzo por distinguirse de los demás, de sus semejantes, para acceder a otro estatuto social percibido como superior y que él considera que forma, por ejemplo, una élite. Sin embargo, esta superioridad es solo una creencia del esnob, explica Frédéric Rouvillois en Histoire du snobisme : la superioridad que el esnob otorga al medio que desea acceder es solo supuesta, soñada e incluso fantasmática. ${ }^{3}$ La distinción implica, sin duda, la exclusión y el desprecio hacia aquellos 
que pertenecen al mismo clan y que por ello pueden considerarse como "gente común, retrasados, inferiores". ${ }^{4}$ Distinción y exclusión forman parte del gusto del esnob.

A medida que va transcurriendo el siglo, vemos que también se van modificando las poses : el esnob no siempre se inclina por el elitismo o el arribismo de antaño, sino que puede tranquilamente optar por el decadentismo y profesar su amor por formas caducas - y por lo tanto, paradójicamente frescas - para poder seguir siendo llamado "esnob".

4 J'suis snob escribe y canta Boris Vian en 1954, también adoptando la primera persona -y tal vez no esté de más señalar que Vian previó igualmente una versión de la letra en femenino ${ }^{5}$ - para retratar con su humor y sorna habituales y en un pulidísimo -y por momentos vulgar-argot a un personaje vestido con camisa de organdí y zapatos de piel de cebú, corbata italiana, un viejo traje carcomido, un anillo de rubí en el dedo del pie, las uñas negras y un pañuelito en el bolsillo, que frecuenta barones con nombre de trombonistas y organiza snobisme-parties todos los viernes, que se deleita con el cine sueco y practica equitación todas las mañanas por puro amor al olor de la bosta. El retrato es por supuesto desopilante, pero certero : el esnob rechaza todo lo popular (odia la CocaCola, ha devuelto su televisión porque lo aburría) y, como contrapartida, ensalza lo único, lo raro, lo inaccesible, lo extravagante, de manera tal que las apariencias se convierten en lo fundamental, y la mirada del otro en el juicio último : usa diamantes como combustible para calentarse; un dolor de hígado vulgar y silvestre es "embellecido" en una úlcera porque es "menos banal y más caro"; no le importa sufrir accidentes automovilísticos siempre y cuando sean a bordo de un Jaguar, y considera que la mejor forma de pasar el tórrido mes de agosto es "en la catrera". "Es en estos pequeños detalles que se es esnob o no", continúa diciendo Vian, antes de reafirmar hacia el final de la canción, en un gesto jubilatoriamente decante: "soy esnob, y todavía más que hace un momento...y cuando esté muerto, ¡quiero una mortaja de Dior !”.

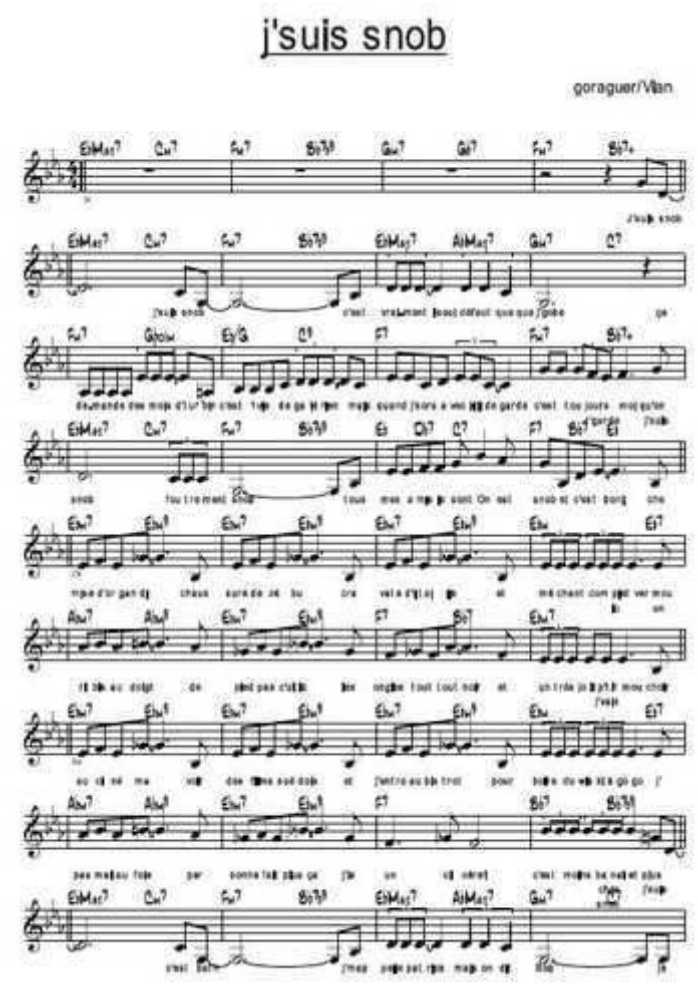

Partitura de "J'suis snob" de Boris Vian (1954) 
Pero ¿qué significa hoy ser esnob ?, ¿cuál es el retrato -imaginario o real- de un escritor esnob ?, ¿a qué aspira, qué le atrae ?, ¿cómo es la biblioteca de un esnob ? Si el esnobismo se relaciona, en gran medida, con la pertenencia -o más bien, con el deseo de pertenencia- a una clase social, económica o cultural, el esnob aspira, ante todo, a demarcarse del resto a través de la novedad, no solo en la apariencia (la vestimenta por ejemplo) sino también en las artes ${ }^{6}$, en el lenguaje (gestos, uso de palabras extranjeras, modismos) o el gusto (por saborear ciertos platos o determinados ingredientes, por practicar algunos deportes). Existe entonces una gran diversidad de esnobismos que, a su vez, varían con el tiempo. Como el límite entre lo novedoso -noción en esencia fugaz- y la moda es muy versátil, lo novedoso corre el riesgo de perder rápidamente interés, porque una vez que se instala en el gusto y se propaga como moda, desaparece aquel rasgo distintivo siempre deseado $\mathrm{y}$, en consecuencia, el sentimiento de poseer un objeto privilegiado. De ahí que el esnob, más especialmente el escritor esnob, discrepe con su presente y sea un adepto de la contracorriente. Del mismo modo que rehúye de su grupo, y aquí encuentra un punto en común con el tránsfugo, es un disidente del presente que busca un refugio en otro lugar : ya sea en el pasado, en la extravagancia, en el artificio. Todo lugar es superior al "aquí y ahora" mientras que lo mantenga alejado de ese mal tan temido, la muchedumbre, el vulgo ; en un sentido más amplio, la vulgaridad.

6 Concepto escurridizo si los hay y, en ese sentido, semejante al de "vanguardia", pareciera que es una de esas nociones que nacen muertas o que, de solo pronunciarlas, se vuelven inoperantes. El deseo o la necesidad de ser siempre distinto, siempre inusual, siempre literalmente extraordinario, suele traducirse en una enorme versatilidad, ya que el verdadero esnob busca destacarse y por lo tanto rehúye de las convenciones como de la peste, aunque busca la aprobación o la admiración de aquellos para los cuales adopta y hasta encarna las diferentes posturas o poses que permiten su identificación como tal. Al igual que sucedía con las vanguardias, la necesidad de ser siempre de avanzada, de dar en permanencia el último grito del momento se acompaña, en la modernidad tardía, de una aceleración que es propia de la época, y que Hartmut Rosa ${ }^{7}$ identifica en tres planos fundamentales : la aceleración técnica, la aceleración de las transformaciones sociales y la aceleración del ritmo de vida. Esta celeridad que afecta a todos los planos de la existencia no perdona ni al esnob, que se ve obligado no solo a multiplicar sus experiencias, sino a adaptar en permanencia sus gestos y artificios, motivo por el cual la moda, caprichosa casi por definición, suele ser un territorio ideal para la manifestación de su afectación.

El mundo del esnob se define entre esas coordenadas : inasible, impopular, una discreción que no alcanza, sin embargo, a la mirada. Ver, y por sobre todo ser visto, es lo importante para el esnob. El arte, en el que justamente la transgresión es visible, promueve espectáculos, exposiciones, tendencias, inauguraciones (vernissage, palabra de gran circulación); todos comparten un mismo gesto: la mirada. No sorprende que el esnobismo profese el arte de la mirada. Pero hacer referencia a la mirada implica también mencionar la imitación, tal vez la esencia del esnobismo junto con el deseo mismo por distinguirse. No es casual, entonces, que la aspiración por integrar ese grupo, que él considera superior, y por aparentar el prestigio de ese mismo grupo -en definitiva : ser lo que no se es-, lo convierta en un gran imitador. ${ }^{8}$

Si parafraseamos esta afirmación de Rouvillois, podríamos decir que en el campo argentino se descubren muchos "intrusos" o "grandes imitadores". Más aún cuando pensamos en una "identidad cultural" que se construyó siempre mirando, y deseando, al otro, el europeo. Y es Borges, tal vez el escritor menos argentino o precisamente por ello 
el más argentino de todos, quien define así al esnobismo : "La más sincera de las pasiones argentinas." Justamente, en una carta acerca del escritor argentino -en quien podríamos apreciar un cierto esnobismo cosmopolita-, Emil Cioran ofrece, aunque no fuera su propósito, algunos rasgos que resumen las contradicciones que habitan el mundo del esnob. Al disculparse por haber declinado la invitación para participar en el homenaje al escritor, Cioran explica que la desgracia de ser reconocido se ha cernido sobre él, Borges, y que citarlo no haría más que precipitar su caída. Merece algo mejor, sostiene Cioran : "[Borges] mérite de demeurer dans l'ombre, dans l'imperceptible, de rester aussi insaisissable et aussi impopulaire que la nuance. Là, il était chez lui." ${ }^{10}$ Inasible e impopular, el lugar que Cioran crea, y desea, para Borges parece ser expresivo de ese miedo que abruma al esnob : ser como todo el mundo.

Ser como todo el mundo es precisamente lo que no fue Victoria Ocampo, figura faro en cuanto al esnobismo argentino se refiere aunque quizás por los motivos equivocados. Difícil, en todo caso, pensar el esnobismo del Río de la Plata sin pensar en la fundadora de SUR, o en la constelación literaria que se traza alrededor de su figura y de otras figuras tutelares -cada una con sus diversas aristas- que este dossier se propone indagar. $* * *$

10 El número que aquí presentamos está organizado en cuatro secciones, precedidas por un "Hors d'œuvre" en el que, a modo de introducción o fino entremés, Sylvia Molloy y Edgardo Cozarinsky -a quienes agradecemos, junto con sus respectivos editores, el interés y su consentimiento para que los artículos integren este número- analizan la figura del dandi desde perspectivas distintas : el de la pose como "gesto político" y la percepción del dandi como cultor de una elegancia de la vestimenta y de los modales. En "La política de la pose" -publicado en el libro Poses de fin de siglo: desbordes del género en la modernidad-, Molloy afirma que durante el siglo XIX la cultura es interpretada como un cuerpo y el género preferido, en tanto forma cultural, es la exhibición: pero exhibir es más que mostrar, es hacerlo de determinada manera, poniendo el acento en aquello que se quería hacer visible. Esta "visibilidad acrecentada" es, finalmente, una pose. "Gesto decisivo en la política cultural" de la Hispanoamérica finisecular, la pose expresa las "inquietudes e ideales" de una época y continente. En el artículo que aquí se presenta, Molloy reflexiona sobre la carga transgresiva de la pose homoerótica y cómo esta problematiza el género.

11 Por su parte, Edgardo Cozarinsky indaga en la vestimenta y en la "puesta en escena social" que el dandi hace con ella. A través de un breve recorrido histórico sobre el dandismo, su surgimiento y sus avatares actuales, el texto «El dandismo y la elegancia como invisibilidad de la apariencia ", brinda algunas anécdotas legadas por Brummell (el "Beau Brummell") y explora la concepción "brummelliana" que Thackeray tenía del dandi, testigo y cronista del ocaso de esta figura. El dandismo para Cozarinsky no se limita a una "disciplina exigente de la elegancia", a un refinamiento opuesto a lo llamativo -que por cierto, asegura el autor, pocos practican- ; habría otro dandismo, una "especie de elegancia moral" que cultiva la amabilidad, algo así como "poner cómodo al desigual".

12 La imagen y la representación del esnob es el eje de la primera sección, "El esnob frente a su espejo". Ricardo Loebell, en su artículo " Augusto d'Halmar : una snobografía », ensaya una definición del esnob a partir de su vínculo con el snobógrafo, es decir el observador que escribe sobre el esnob. A su vez, siempre con el foco en la percepción del otro (desde la mirada europea, el otro es el exótico), el autor rastrea la recepción del esnob en América Latina como reflejo de la sociedad europea. La atención de los otros dos textos 
que completan esta sección está puesta en Lucio V. Mansilla, autor al que se vincula con Baudelaire y Darío. En «La desintegración del esnob : la fotografía en la obra de Charles Baudelaire y Lucio V. Mansilla ", Mariana de Cabo analiza, a partir de la figura del "esnob victorioso", el uso de la escritura y la fotografía en Mansilla y Baudelaire como mecanismos de simulación. La pérdida de tiempo que insume contestar una tarjeta postal, el sentimiento de hartazgo de Mansilla y Darío ante esta práctica, "una manía esnob", es el punto de partida del artículo "Mansilla y Darío entre postales: ¿celebridad o esnobismo?». Allí, Inés de Mendonça interroga a estos dos autores en tanto "figuras oscilantes" -críticas hacia la moda pero también tentadas por ella- a partir del vínculo entre dos rasgos contradictorios del esnob, la distinción y la popularidad.

"Esnobismos del SUR o el deseo del otro" es el título de la siguiente sección que se concentra en el círculo de la revista Sur y en particular en Victoria Ocampo, Jorge Luis Borges y Adolfo Bioy Casares. ¿Fue realmente Victoria Ocampo esnob? La posteridad parece haberla encerrado en ese epíteto, subraya Victoria Liendo antes de dedicarse, justamente, a cuestionar y desestabilizar ese mismo epíteto. "Victoria Ocampo : una snob para el desierto" recupera el sentido del "esnobismo de la modernidad" que practicó Ocampo a través de una indagación acerca de los alcances y malentendidos del esnobismo de la fundadora de Sur. El grupo SUR es también el foco del trabajo de Mariano García, quien explora distintas manifestaciones del esnobismo argentino. Su trabajo ("Ese jardín vedado al medio pelo. Capítulos del esnobismo en Victoria Ocampo, Adolfo Bioy Casares y Jorge Luis Borges") nace de una premisa que ya estaba en la formulación de Thackeray o de Virginia Woolf: "es preciso que uno mismo sea esnob para sufrir por causa del esnobismo de los otros". En otras palabras, la imitación del otro, que se halla en la esencia del esnobismo, impone un doble juego : criticar al otro en tanto esnob supone, en primer lugar, asumirse uno mismo como esnob.

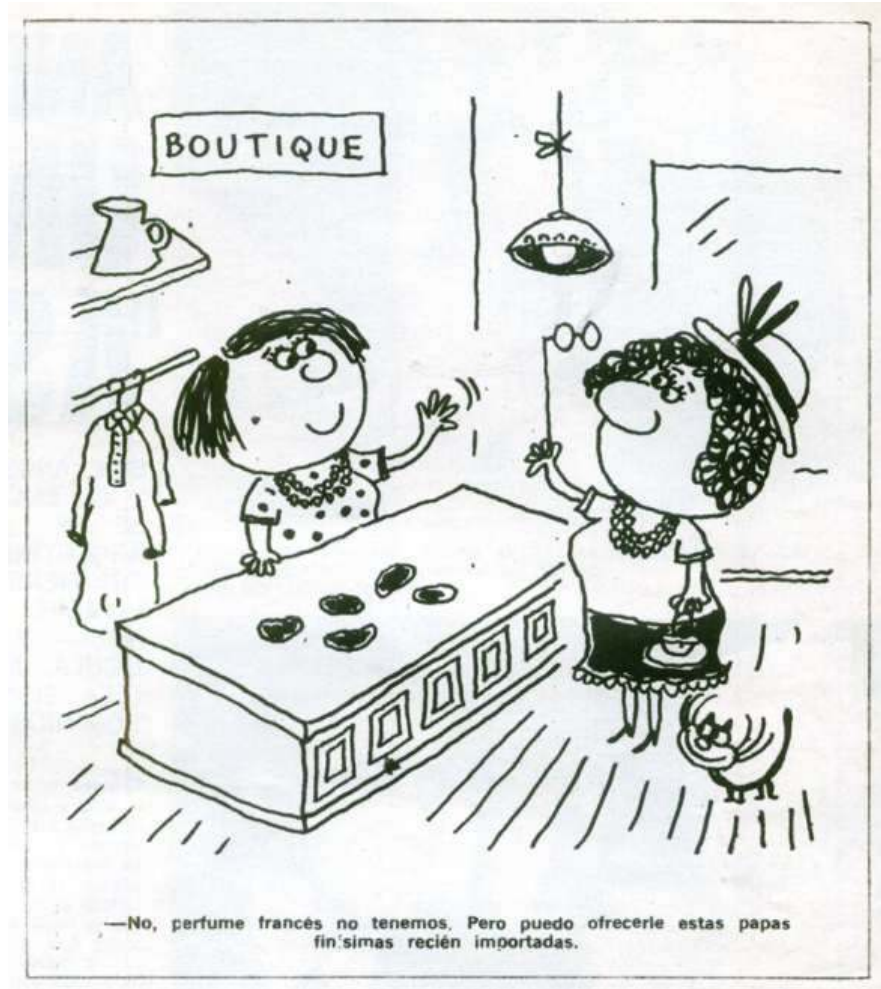

LANDRÚ (JUAN CALOS COLOMBRES), REVISTA TÍA VICENTA 

política". La realidad política argentina asoma en el trabajo de María Julia Rossi, "Las amenazas de una dinastía espuria. Sirvientes que no sirven en Manuel Mujica Lainez". Allí la autora revisa el cuento "El retrato amarillo" y la novela La casa para proponer una contralectura: aquella que se detiene en el punto de vista de las sirvientas, sus protagonistas. En "Esnobismos de la derecha : Lesca, el fascista irreductible, de Jorge Asís", Mariano Sverdloff analiza el esnobismo de la extrema derecha a partir de la siguiente pregunta : ¿cómo definir el esnobismo de la violencia y del fascismo? Sverdloff lee algunos vínculos que la novela insinúa (de Maurras a Perón, de Drieu la Rochelle a Victoria Ocampo, de Vichy al neoliberalismo) y examina la figura pública del propio Asís, en quien ve la pose de dandi que irradia un "esnobismo agradable" : a pesar de las críticas que suscita, pareciera que hoy en día, "citar a Asís es de buen tono"; un gesto decididamente esnob. Finalmente, el artículo de Gerardo Jorge considera la poesía de Arturo Carrera como una obra inscripta en el presente : esta es la hipótesis de su trabajo, "Un lirismo sine nobilitate: moda, mundanidad y sociolectos como inscripciones del presente en la poesía de Arturo Carrera", en el que Jorge aleja las imágenes de esnobismo y superficialidad del neobarroco, como generalmente la crítica asocia, para estudiar ciertas "marcas de 'modas' culturales y académicas" y algunos usos sociolectales de la lengua, entre otros materiales.

Mariana Dimópulos y Victoria Lescano proponen sendas lecturas sobre el gusto culinario y la vestimenta en "Moda, gustos y costumbres", sección que cierra las colaboraciones críticas del dossier. En "Del gusto y sus disputas", Dimópulos analiza la historia del término "gusto", en sus orígenes asociado a la esfera culinaria o bien a la preferencia personal. El siglo XIX ve aparecer dos tipos sociales que parecieran querer escapar a la generalización del gusto, el dandi y el esnob. En la comida, afirma Dimópulos, se reconoce también esta práctica de la distinción que ambos encarnan. Por su parte, Victoria Lescano se focaliza en la vestimenta como expresión de una clase social en su texto "El elogio de ropas color pan quemado y la paquetería en Buenos Aires". A través de algunos textos de la revista La Moda de Juan Bautista Alberdi y de algunas ficciones de Silvina Ocampo y Silvina Bullrich, Lescano describe los distintos estilos como expresión de una época determinada y del paisaje literario argentino.

Como cierre, el dossier propone dos traducciones que prolongan, de alguna manera, la discusión : "El esnobismo, una cuestión de topografía social”, con traducción de Ricardo Torre, es el prefacio a un libro de entrevistas que Adèle Van Reeth le hizo a Raphaël Enthoven y que apareció en el libro El esnobismo ; y "El hombre de la literatura" de Gérard Dessons ("L'homme de la littérature"), traducido por Christian Galdón.

17 A los colaboradores y traductores, a los editores que autorizaron la reproducción, y a Francisco Espino, a quien debemos la puesta en línea del número, nuestro grandísimo agradecimiento por haber hecho posible este número. 


\section{NOTES}

1. M. Proust, Sodome et Gomorrhe II, Gallimard, Bibliothèque de la Pléiade, 1954, p. 750.

2. Cf. "El esnobismo, una cuestión de topografía social", entrevista a Raphaël Enthoven de la que este número ofrece su traducción.

3. F. Rouvillois, Histoire du snobisme, París, Flammarion, 2010, p. 14.

4. Ibid., p. 13.

5. Para consultar las dos versiones, ver los números 172 y 173 en la lista completa de las canciones de Vian : http://www.boris-vian.net/fr/liste.html\#notes

6. El cine, la pintura, la música, el teatro, la literatura, obviamente, pero también pensamos, por ejemplo, en la filosofía. Ya es casi una anécdota cómo le tout Paris acudía a las clases de filosofía de Henri Bergson en el Collège de France al punto que en el año 1914, en los albores de la Primera Guerra Mundial, la influencia de Bergson era "el" tema más parisino del momento.

7. Hartmut Rosa, Accélération. Une critique sociale du temps, Paris, La Découverte, coll. "Théorie critique ", 2010, $474 \mathrm{p}$.

8. F. Rouvillois, op. cit., p. 19.

9. “¿Confesaré que, movido por la más sincera de las pasiones argentinas, el esnobismo, yo estaba enamorado de ella y que su muerte me afectó hasta las lágrimas? Quizá ya lo haya sospechado el lector.", "Zahir" en El Aleph, Obras Completas, Emecé, 1974.

10. Se trata de una carta de 1976 dirigida a Fernando Savater. E. Cioran, "Borges ", Exercices d'admiration. Essais et portraits, Paris, Éditions Gallimard, 1986, p. 161. El subrayado es nuestro.

\section{AUTHORS}

\section{MARIANA DI CIÓ}

Université Sorbonne Nouvelle, Paris III

\section{MAYA GONZÁLEZ ROUX}

IdIHCS (UNLP) - Conicet 